\title{
Burden of Breast Cancer in Iranian Women is Increasing
}

\author{
Abdolhamid Sharifian ${ }^{1}$, Mohamad Amin Pourhoseingholi ${ }^{2 *}$, Majid Emadedin ${ }^{2}$ \\ Mohammad Rostami Nejad ${ }^{3}$, Sara Ashtari ${ }^{3}$, Nastaran Hajizadeh ${ }^{4}$, Seyed Alireza \\ Firouzei $^{2}$,Seyed Jalil Hosseini ${ }^{2}$
}

\begin{abstract}
Background: Breast cancer (BC) is the leading cause of oncological death for women, in both developed and developing countries. In Iran, breast cancer ranks first among cancers diagnosed in women. The aim of this study was to present the burden of this cancer including incidence, mortality and years life lost (YLL) due to breast cancer in Iranian women. Materials and Methods: National incidence data from the Iranian annual National Cancer Registration reports from 2003 to 2009 and national death statistics reported by the Ministry of Health and Medical Education from 1995 to 2010 , stratified by age group, were included in this analysis. Also calculated YLLs provided by the Institute for Health Metrics and Evaluation (IHME) for the years 1990, 1995, 2000, 2005 and 2010 were employed to express the years lost due to BC for Iranian women. Results: The general mortality rate of breast cancer increased during these years from 0.96 to 4.33 per 100,000 and incidence increased from 16.0 to 28.3 per 100,000 for the years under study. YLLs calculated by IHME showed both increasing and decreasing patterns, with a tendency for stabilization. Conclusions: The burden of breast cancer for Iranian women is still increasing. Thus, health education programs to inform women regarding the signs and risk factors, and national screening to facilitate early diagnosis are needed for the female community in Iran.
\end{abstract}

Keywords: Breast cancer - mortality - incidence - burden - Iran

Asian Pac J Cancer Prev, 16 (12), 5049-5052

\section{Introduction}

Breast cancer $(\mathrm{BC})$ is the leading cause of oncological death for women, in both developed and developing countries (Jamal et al., 2011). Global incidence trend of breast cancer is increasing especially in countries with a low rate of incidence (Montazeri et al., 2008) and Iran is not an exception (Jafari-Koshki et al., 2014). It has been reported that each year over 502,000 women die from the disease, worldwide (World Health Organization., 2009) and in Iran, BC ranks first among cancers diagnosed in women (Sadjadi et al., 2005; Safaee et al., 2008) with comprising $24.4 \%$ of all malignancies (Mousavi et al., 2009). This cancer is also the most frequent cancer in women of Tehran (Mohagheghi et al., 2009). Its mortality rate increased (Taghavi et al., 2012), with similar pattern to expected mortality rates in general Iranian women population (Haghighat et al, 2012). Early detection of breast cancer plays the leading role in reducing mortality and improving the patients' prognosis among women (Elmore et al., 2005; Hoerger et al., 2011). So in some cancers like $\mathrm{BC}$, we expected to see more long-term disease free survival (Rahimzadeh et al., 2014).

Hence, it is necessary and important to get accurate projections of breast cancer burden including; mortality rates, incidence and years of life lost due to this malignancy, this study tried to present the trends of mortality, incidence and YLL (years of life lost) from $\mathrm{BC}$ for Iranian women according to latest population data sources, in order to provide update information regarding the burden of this cancer for Iranian women population.

\section{Materials and Methods}

The data for this study extracted from three sources; first, National death Statistic Reported by the MOH\&ME from 1995 to 2000 (registered death statistics for Iranian population at the Information Technology and Statistic Management Center, $\mathrm{MOH}$ and ME) and from 2001 to 2010 (published by MOH and ME) (Naghavi., 2002; Naghavi., 2003; Naghavi., 2004; Islamic Republic of Iran, Ministry of Health and Medical Education, Center for Network management, Information Technology and Applied Researches group Center., 2012) stratified by age group and cause of death (coded according to the International Classification of Diseases [ICD-10] are included in this analysis. Breast cancer [ICD-10: $\mathrm{C}_{50}$ ] were expressed as the annual mortality rates/100,000,

${ }^{1}$ Gandy General Hospital, ${ }^{2}$ Infertility and Reproductive Health Research Center, ${ }^{3}$ Gastroenterology and Liver Diseases Research Center, Research Institute for Gastroenterology and Liver Diseases, ${ }^{4}$ Department of Biostatistics, Shahid Beheshti University of Medical Sciences, Tehran, Iran*For correspondence: Aminphg@gmail.com 
overall, by age group (15-49 and $\geq 50$ years of age). Second, national incidence data derived from Iranian annual of National Cancer Registration report from 2003 to 2009 (Islamic Republic of Iran, Ministry of Health and Medical Education, Center for Disease Control \& Prevention. Noncommunicable Deputy, Cancer Office, 2009), which provided according to age standardized rate (ASR). Finally, the calculated YLLs which provide by Institute for Health Metrics and Evaluation (IHME) for years 1990, 1995, 2000, 2005 and 2010 (Institute for Health Metrics and Evaluation., 2014) were employed to express the years lost due to BC for Iranian women.

The populations of Iran in 1995-2010 were estimated, using the census from 1996 and 2005 conducted by Statistics Centre of Iran and its estimation according to population growth rate for years before and after national census.

\section{Results}

All death records for women due to BC from 1995 to 2010 and the incidence for new cases of BC from 2003 to 2009 are included in this study. The mortality rate of

Table 1. Age specific Rate (per 100,000) and Total Crud Rate (per 100,000) for Breast Cancer Mortality in Iranian Women

\begin{tabular}{lccc}
\hline Year & $15-49$ Years & $\geq 50$ Years & Crud Rate \\
\hline 1995 & 0.74 & 4.63 & 0.96 \\
1996 & 1.08 & 6.24 & 1.36 \\
1997 & 1.14 & 7.47 & 1.54 \\
1998 & 1.2 & 6.24 & 1.41 \\
1999 & 1.49 & 8.93 & 1.91 \\
2000 & 1.65 & 10.58 & 2.12 \\
2001 & 1.82 & 9.88 & 2.38 \\
2002 & 2.14 & 11.8 & 2.75 \\
2003 & 2.1 & 11.9 & 2.72 \\
2004 & 2.08 & 11.16 & 2.58 \\
2006 & 2.25 & 14.49 & 3.42 \\
2007 & 2.57 & 14.91 & 3.77 \\
2008 & 2.4 & 15.18 & 3.8 \\
2009 & 2.3 & 15.79 & 3.88 \\
2010 & 2.73 & 16.4 & 4.33 \\
\hline
\end{tabular}

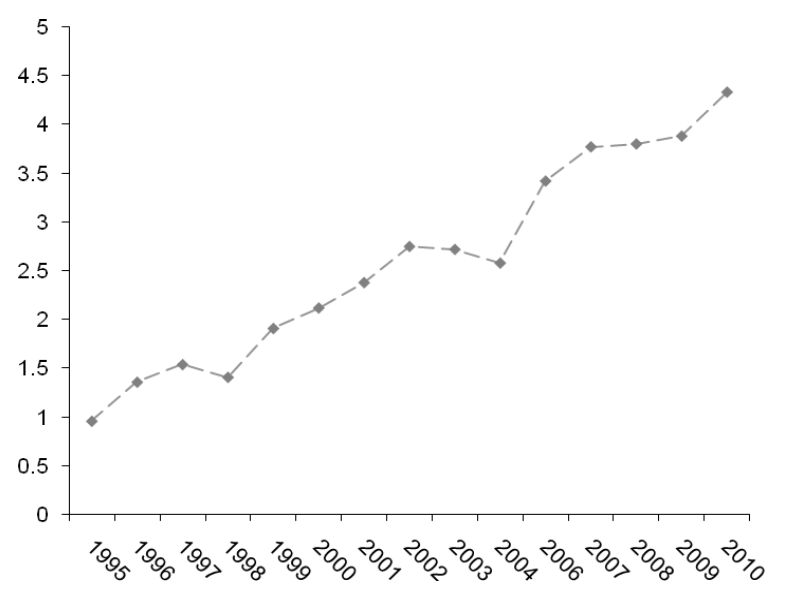

Figure 1. Trend of Breast Cancer Mortality During the Period 1995-2010 per 100,000

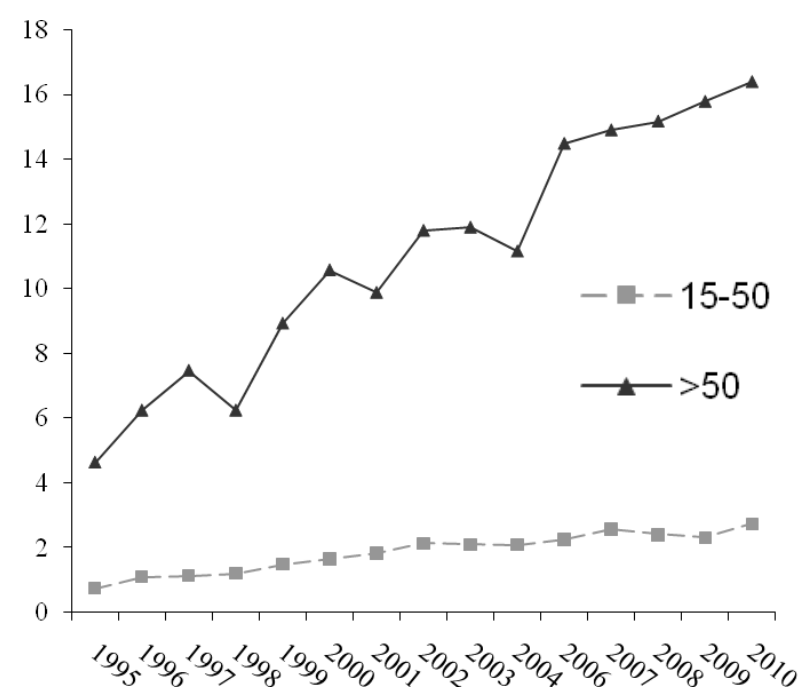

Figure 2. Age Specific Rate (per 100,000) for Breast Cancer Mortality During the Period 1995-2010

Table 2. Crud Rate, ASR and Age specific rate (per $\mathbf{1 0 0 , 0 0 0}$ ) for Breast Cancer Incidence in Iranian Women

\begin{tabular}{llllll}
\hline Year & $\begin{array}{c}<15 \\
\text { Years }\end{array}$ & $\begin{array}{c}15-49 \\
\text { Years }\end{array}$ & $\begin{array}{c}>50 \\
\text { Years }\end{array}$ & $\begin{array}{c}\text { Crude } \\
\text { Rate }\end{array}$ & ASR \\
\hline 2003 & 2.79 & 27.2 & 41.03 & 12.19 & 15.96 \\
2004 & 1.34 & 31.1 & 47.5 & 13.84 & 18.24 \\
2005 & 1.76 & 38.6 & 60.82 & 17.44 & 23.16 \\
2006 & 1.6 & 41.48 & 66.93 & 18.9 & 25.06 \\
2007 & 2.23 & 43.85 & 72.91 & 20.42 & 27.15 \\
2008 & 2.79 & 53.12 & 89.35 & 24.66 & 33.21 \\
2009 & 1.62 & 40.03 & 84.53 & 22.09 & 28.25 \\
\hline
\end{tabular}

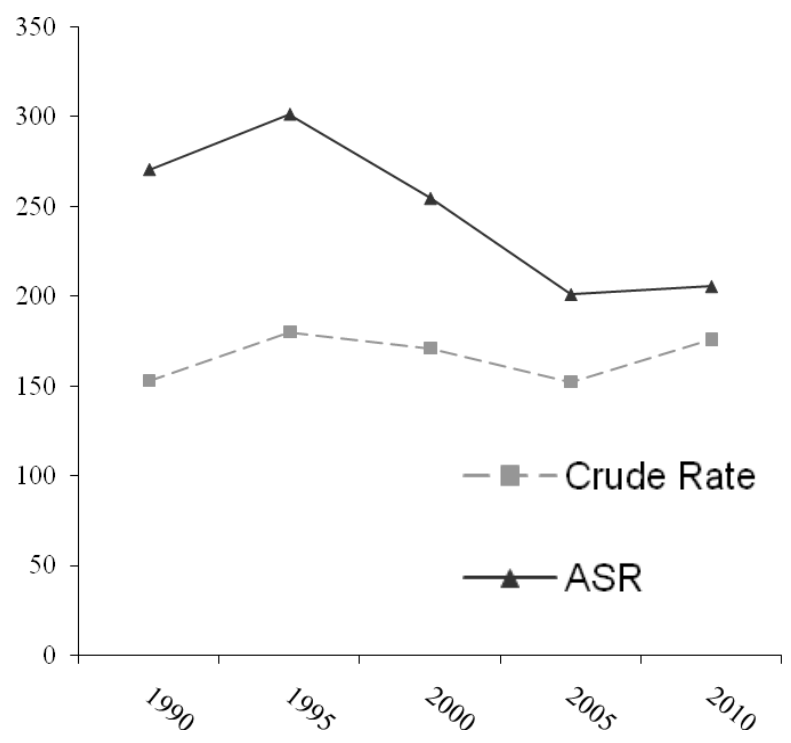

Figure 3. Trend of YLLs Age Specific Rate and Total Rate (per 100,000) for Breast Cancer in Iranian Women According to IHME Estimation

BC increased dramatically during these years from 0.96 to 4.33 per 100,000 (Table1 and Figure1) and its mortality was increasing for age more than 50 years old. For younger age, the rate increased from 0.74 to 2.73 per 100,000 but for older age, it increased sharply from 4.63 to 16.40 per 
Table 3. YLLs Age Specific Rate and Total Rate (per 100,000) for Breast Cancer in Iranian Women According to IHME Estimation

\begin{tabular}{cccccc}
\hline Year & $\begin{array}{c}<15 \\
\text { Years }\end{array}$ & $\begin{array}{c}15-49 \\
\text { Years }\end{array}$ & $\begin{array}{c}>50 \\
\text { Years }\end{array}$ & $\begin{array}{c}\text { Crude } \\
\text { Rate }\end{array}$ & ASR \\
\hline 1990 & 186.89 & 670.21 & 584.59 & 152.8 & 270.35 \\
1995 & 225.01 & 703.26 & 597.69 & 179.7 & 301.15 \\
2000 & 198.47 & 592.46 & 416.55 & 170.9 & 254.31 \\
2005 & 154.42 & 496.12 & 284.63 & 152.2 & 200.77 \\
2010 & 163.96 & 529.76 & 317.92 & 175.64 & 205.28 \\
\hline
\end{tabular}

100,000 (Table1 and Figure 2).

The crude rate and ASR of BC incidence were increased during the period under study and the incidence was higher for older age (Table 2). ASR increased from 15.96 in 2003 to 28.25 in 2009 per 100,000 . On the other hands, the rate was decreased for age under 15 , from 2.79 in 2003 to 1.62 in 2009 , but for other age groups, it was increased (Table 2).

YLLs extracted from IHME indicated that the crude rate of years lost due to BC was 152.8 years per 100,000 in 1990 and it changed to 175.64 years per 100,000 in 2010. But the pattern of trends was inverse for ASR which was 270.35 years per 100,000 in 1990 but it was estimated 205.28 years per 100,000 for 2010 (Table 3 and Figure 3).

\section{Discussion}

There is an increasing trend for burden of breast cancer in Iranian women, although it is still low compared with developing countries. Since the 1990s, age-adjusted mortality rates for $\mathrm{BC}$ have declined in most of developing countries, particularly in the young and middle-aged groups. In the UK and Switzerland, the mortality decreased about 30\% (Bulliard et al., 2006), and most Southern, Northern, and Western European countries showed the declining between $15 \%$ and $25 \%$, or remind stable for Eastern European countries (Hery et al., 2009; Autier et al., 2011). Another study reported that, in Europe the age adjusted mortality rates declined by $6.9 \%$ from 2002 to 2006, with the largest falls in northern European countries (Bosetti et al., 2006). In US, among young women diagnosed with $\mathrm{BC}$, mortality declines have been observed over time, although more rapid gains have been reported to occur in white women (Ademuyiwa et al., 2014). In Asia, Japan, Korea and China an increasing in trends of BC mortality happened (Choi et al., 2006; Katanoda and Yako-Suketomo, 2010; He et al., 2011) which is similar to Iranian patterns.

In European countries, the mortality is decreasing, along with rising incidence rates (Sant et al., 2006), which may be due to more frequent exposure to risk factors of BC including delayed childbearing, lower parity, use of postmenopausal hormone therapy and obesity (Hulka and Moorman., 2008). The declining in mortality rates attributed both to early diagnosis through mammography screening and access to efficient treatments like as adjuvant chemotherapy (Berry et al., 2005). For example an Italian study showed that earlier and steeper decline in breast cancer mortality could be partially attributable to local organized screening program (Gorini et al., 2014) and another study in Spain in the period 1990-2008 revealed that mortality reduction attributable to screening and adjuvant therapy was about 50\% (Vilaprinyo et al., 2012).

Iran is the western part of Asia, with rising incidence of BC. Studies have shown that the age distribution of breast cancer in Iran is nearly one decade lower than their counterparts in developed countries (Mousavi et al., 2006; Mousavi et al., 2007).

Early detection of breast cancer plays the leading role in reducing mortality rates and improving the patients' prognosis among women (Elmore et al., 2005; Hoerger et al., 2011). In Western countries, it is proposed that maximal reductions in burden of breast cancer could be achieved through optimizing treatment use, followed by increasing screening use and obesity prevention (Mandelblatt et al., 2013).

Our study indicating that the trend of BC mortality and incidence in Iranian women were increasing in recent years, however the calculated YLLs by IHME, indicates approximately a level-off pattern. Definitely providing more accurate data needs to data linkage of a cancer Registry data containing survival records and death registry records at the same time interval to prepare more accurate prediction regarding this malignancy (Haghighat et al., 2012).

In Iran, no national screening program for BC conducted yet and studies indicated that the women's awareness of $\mathrm{BC}$ warning signs and effective screening were very inadequate (Yavari and Pourhoseingholi., 2007; Montazeri et al., 2008). The World Health Organization guidelines on early detection of $\mathrm{BC}$ included two approaches: screening that focuses on detecting cancer in asymptomatic women and clinical down-staging (or early diagnosis) that focuses on detecting cancer in early stage (Corbex et al., 2012; World Health Organization., 2013). It seems that, to middle and lower-income countries, clinical down-staging is a cheap and easy-to-implement alternative to screening, can result in women being diagnosed with earlier and curable disease rather than later with mainly incurable BC (Burton and Bell, 2013). Besides, for Iranian women, health education program would be beneficial to reduce the lack of women's awareness regarding BC, to control the burden in future.

\section{References}

Ademuyiwa FO, Gao F, Hao L, et al (2014). US breast cancer mortality trends in young women according to race. Cancer, 121, 1469-76

Autier P, Boniol M, Gavin A, Vatten LJ (2011). Breast cancer mortality in neighbouring European countries with different levels of screening but similar access to treatment: trend analysis of WHO mortality database. BMJ, 28, 343.

Berry DA, Cronin KA, Plevritis SK, et al (2005). Effect of screening and adjuvant therapy on mortality from breast cancer. N Engl J Med, 353, 1784-92.

Bosetti C, Bertuccio P, Levi F (2012). The decline in breast cancer mortality in Europe: an update (to 2009). Breast, 21, 77-82. 


\section{Abdolhamid Sharifian et al}

Bulliard JL, La Vecchia C, Levi F (2006). Diverging trends in breast cancer mortality within Switzerland. Ann Oncol, 7, 57-9.

Burton R, Bell R (2013). The global challenge of reducing breast cancer mortality. Oncologist, 18, 1200-2.

Choi Y, Kim Y, Park SK, et al (2006). Age-period-cohort analysis of female breast cancer mortality in Korea. Breast Cancer, 13, 266-71.

Corbex M, Burton R, Sancho-Garnier H (2012). Breast cancer early detection methods for low and middle income countries, a review of the evidence. Breast, 21, 428-34.

Elmore JG, Armstrong K, Lehman CD, Fletcher SW (2005). Screening for breast cancer. JAMA, 293, 1245-56.

Gorini G, Zappa M, Cortini B, et al (2014). Breast cancer mortality trends in Italy by region and screening programme, 1980-2008. J Med Screen, 21, 189-93.

Haghighat S, Akbari ME, Ghaffari S, Yavari P (2012). Standardized breast cancer mortality rate compared to the general female population of Iran. Asian Pac J Cancer Prev, $13,5525-8$.

He M, Guo Q, Hu G (2011). Reversed urban-rural differences in breast cancer mortality (China, 2002-2008). Breast Cancer Res Treat, 126, 231-4.

Hery C, Ferlay JM, Boniol M, Autier P (2009). Quantification of changes in breast cancer incidence and mortality since 1990 in 35 countries with Caucasian-majority populations. Ann Oncol, 19, 1187-94.

Hoerger TJ, Ekwueme DU, Miller JW, et al (2011). Estimated effects of the national breast and cervical cancer early detection program on breast cancer mortality. Am J Prev Med, 40, 397-404.

Hulka BS, Moorman PG (2008). Breast cancer: hormones and other risk factors. Maturitas, 61, 203-13.

Islamic Republic of Iran. Ministry of health and medical education. center for disease control \& prevention. noncommunicable deputy. cancer office (2009). Iranian Annual of National Cancer Registration Report.

Islamic Republic of Iran (2012). Ministry of health and medical education, center for network management, information technology and applied researches group center. Death report from 29 provinces in Iran from 2006 to $2010.1^{\text {st }}$ edition. Ministry of Health and Medical Education, Tehran, Iran.

Institute for Health Metrics and Evaluation (IHME) (2014). Available at: http://www.healthdata.org/gbd

Jafari-Koshki T, Schmid VJ, Mahaki B (2014). Trends of breast cancer incidence in Iran during 2004-2008: a Bayesian space-time model. Asian Pac J Cancer Prev, 15, 1557-61.

Jemal A, Bray F, Center MM, et al (2011). Global cancer statistics. CA Cancer J Clin, 61, 69-90.

Katanoda K, Yako-Suketomo H (2010). Comparison of time trends in breast cancer mortality (1990-2006) in the World, from the WHO mortality database. Jpn J Clin Oncol, 40, 182.

Mandelblatt J, van Ravesteyn N, Schechter C, et al (2013). Which strategies reduce breast cancer mortality most? Collaborative modeling of optimal screening, treatment, and obesity prevention. Cancer, 119, 2541-8.

Mohagheghi MA, Mosavi-Jarrahi A, Malekzadeh R, Parkin M (2009). Cancer incidence in tehran metropolis: the first report from the tehran population-based cancer registry, 1998-2001 Arch Iran Med, 12, 15-23.

Montazeri A, Vahdaninia M, Harirchi I, et al (2008). Breast cancer in Iran: need for greater women awareness of warning signs and effective screening methods. Asia Pac Fam Med, 7, 6 .

Mousavi SM, Gouya MM, Ramazani R, et al (2009). Cancer incidence and mortality in Iran. Ann Oncol, 20, 556-63.

Mousavi SM, Montazeri A, Mohagheghi MA, et al (2007).
Breast cancer in Iran: an epidemiological review. Breast $J, 13,383-91$.

Mousavi SM, Mohaghegghi MA, Mousavi-Jerrahi A, et al (2006). Burden of breast cancer in Iran: a study of the Tehran population based cancer registry. Asian Pac J Cancer Prev, 7, 571-4.

Naghavi M (2002). Death report from 18 provinces in Iran. $1^{\text {st }}$ edition. Ministry of Health and Medical Education, Tehran, Iran.

Naghavi M (2003). Death report from 23 provinces in Iran. $1^{\text {st }}$ edition. Ministry of Health and Medical Education, Tehran, Iran.

Naghavi M (2004). Death report from 29 provinces in Iran. $1^{\text {st }}$ edition. Ministry of Health and Medical Education, Tehran, Iran.

Rahimzadeh M, Baghestani AR, Gohari MR, Pourhoseingholi MA (2014). Estimation of the cure rate in Iranian breast cancer patients. Asian Pac J Cancer Prev, 15, 4839-42.

Sadjadi A, Nouraie M, Mohagheghi MA, et al (2005). Cancer occurrence in Iran in 2002, an international perspective. Asian Pac J Cancer Prev, 6, 359-63.

Safaee A, Moghimi-Dehkordi B, Zeighami B, et al (2008). Predictors of quality of life in breast cancer patients under chemotherapy. Indian J Cancer, 45, 107-11.

Sant M, Francisci S, Capocaccia R, et al (2006). Time trends of breast cancer survival in Europe in relation to incidence and mortality. Int J Cancer, 119, 2417-22.

Taghavi A, Fazeli Z, Vahedi M, et al (2012). Increased trend of breast cancer mortality in Iran. Asian Pac J Cancer Prev, 13, 367-70.

Vilaprinyo E, Puig T, Rue M (2012). Contribution of early detection and adjuvant treatments to breast cancer mortality reduction in Catalonia, Spain. PLoS One, 7, 30157.

World Health Organization (2013). Cancer Control: Knowledge Into Action. "Early detection." Available at http://whqlibdoc. who.int/publications/2007/9241547338_eng.pdf. Accessed August 10,

World Health Organization (2009). Mortality database. WHO, 2-6.

Yavari P, Pourhoseingholi MA (2007). Socioeconomic factors association with knowledge and practice of breast selfexamination among Iranian women. Asian Pac J Cancer Prev, 8, 618-22. 